CLINICAL STUDY

\title{
Low-activity (2.0 GBq; 54 mCi) radioiodine post-surgical remnant ablation in thyroid cancer: comparison between hormone withdrawal and use of rhTSH in low-risk patients
}

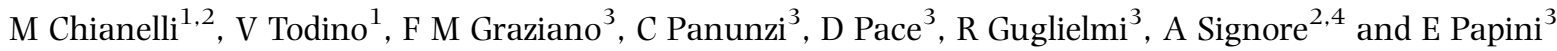 \\ ${ }^{1}$ Nuclear Medicine Unit, Department of Diagnostics, Regina Apostolorum Hospital, Via San Francesco 50, O0041 Albano, Rome, Italy, ${ }^{2}$ Department of \\ Nuclear Medicine and Molecular Imaging, UMCG, University of Groningen, Groningen, The Netherlands, ${ }^{3}$ Endocrinology Unit, Department of Metabolic \\ and Digestive Diseases, Regina Apostolorum Hospital, Albano, Rome, Italy and ${ }^{4}$ Department of Nuclear Medicine, S. Andrea Hospital, 'Sapienza' \\ University, Rome, Italy \\ (Correspondence should be addressed to M Chianelli; Email: marcochianelli@libero.it)
}

\begin{abstract}
Objective: (a) To compare the efficacy of low-activity (2 GBq; $54 \mathrm{mCi}$ ) ${ }^{131} \mathrm{I}$ ablation using L-thyroxine withdrawal or rhTSH stimulation, and (b) to assess the influence of thyroid remnants volume on the ablation rate.

Design: Patients underwent neck ultrasound, ${ }^{131}$ I neck scintigraphy and radioiodine uptake. Posttherapy whole body scan (WBS) was acquired after 4-6 days. Ablation was assessed after 6-12 months by WBS, Tg and TgAb following L-thyroxine withdrawal.

Methods: Group A: preparation by $\mathrm{L}-\mathrm{T}_{4}$ withdrawal (37 days); 21 patients received ${ }^{131} \mathrm{I}(2.02 \pm$ $0.22 \mathrm{GBq} ; 54.6 \pm 5.9 \mathrm{mCi}$ ) and on the day of treatment, $\mathrm{TSH}, \mathrm{Tg}$, TgAb were measured; Group B: stimulation by rhTSH; 21 patients received ${ }^{131} \mathrm{I}(1.97 \pm 0.18 \mathrm{GBq} ; 53.2 \pm 4.9 \mathrm{mCi}) 24 \mathrm{~h}$ after the second injection of rhTSH $(0.9 \mathrm{mg})$ and TSH, Tg and TgAb were measured after 2 days.

Results: At follow-up, 90.0\% of patients from group A and $85.0 \%$ of patients from group B had Tg levels $<1 \mathrm{ng} / \mathrm{ml}$; no uptake was observed in $95.2 \%$ and in $90.5 \%$ of patients from group A or B respectively, with no statistical differences for both ablation criteria. Before ${ }^{131}$ I treatment, small thyroid remnants $(<1 \mathrm{ml})$ were detected by US in $<25 \%$ of all patients.

Conclusions: The use of rhTSH for the preparation of low-risk patients to ablation therapy with low activities of ${ }^{131} \mathrm{I}(2 \mathrm{GBq} ; 54 \mathrm{mCi})$ is safe and effective and avoids hypothyroidism. The presence of thyroid remnants smaller than $1 \mathrm{ml}$ at US evaluation had no effect on the ablation rate.
\end{abstract}

European Journal of Endocrinology 160 431-436

\section{Introduction}

Differentiated thyroid cancer is a neoplasm with a relatively indolent course with high long-term survival. However, tumour recurrence is common, affecting up to $20 \%$ of patients, sometimes decades after the initial therapy $(1,2)$. Despite some controversies, it is generally accepted that post-surgical remnant ablation by ${ }^{131} \mathrm{I}$ in patients with low risk $\left(\mathrm{pT}_{1}\right.$ greater than $1 \mathrm{~cm}$, and pT2 with no extrathyroid involvement) reduces the risk of mortality and tumour recurrence $(3,4)$.

Thyroid ablation by ${ }^{131} \mathrm{I}$ must be performed under high levels of TSH to maximise thyroid uptake and efficacy of treatment. In low-risk patients, however, different activities of ${ }^{131} \mathrm{I}$ have been used (1.1-3.7 GBq; $30-100 \mathrm{mCi}$ ) with different regimens of TSH stimulation (3).

In 2004, the European Agency licensed rhTSH for use in thyroid remnant ablation with high activities of ${ }^{131} \mathrm{I}(3.7 \mathrm{GBq} ; 100 \mathrm{mCi})(4,5)$.
The use of rhTSH increases the levels of TSH without the need to induce hypothyroidism; it would also be advantageous to use low activities of radioiodine to reduce the radiation-absorbed dose by the patient. Previous studies on low-activity thyroid remnant ablation using rhTSH have produced discordant results $(6,7)$. A recent study, however, compared the ablation rate in patients treated with rhTSH with either $3.70 \mathrm{GBq}$ or $1.85 \mathrm{GBq}(100$ or $50 \mathrm{mCi})$ and showed similar efficacy (8). Further studies are needed to assess which is the preferred method for ablation (thyroid hormone withdrawal versus rhTSH stimulation) and which is the lowest activity of ${ }^{131}$ I that can be used for successful ablation.

The aim of the present study was to verify, in a series of low-risk patients, a) the efficacy of thyroid ablation using low activities of ${ }^{131} \mathrm{I}$ ( $2.0 \mathrm{GBq} ; 54 \mathrm{mCi}$ ) by thyroid hormone withdrawal or rhTSH stimulation, and b) the influence of thyroid remnant volume, measured by ultrasound (US), and ${ }^{131}$ I uptake on the ablation rate. 


\section{Patients and methods}

The rate of ablation was compared in a series of consecutively enrolled patients who gave their written consent and were randomised into two groups. The study was conducted in accordance with the Helsinki declaration and was approved by the ethics committee of the hospital. All patients had papillary cancer or minimally invasive follicular cancer, with a tumour node metastases stage $\mathrm{pT}_{1}$, larger than $1 \mathrm{~cm}$ or less than $1 \mathrm{~cm}$ if in the presence of multiple foci and could be considered patients at low risk of recurrence (stage I; tumour node metastases (TNM; staging according to AJCC 2002)) (9). No patient had positive cervical lymph nodes at the time of treatment as evaluated by US. All patients underwent total thyroidectomy or near-total thyroidectomy and, after surgery, began treatment with a TSH suppressive dose of $\mathrm{L}^{\mathrm{T}} \mathrm{T}_{4}$. All patients adhered to a lowiodine diet for 2 weeks before receiving ${ }^{131}$ I. Patients with positive Tg autoantibodies were excluded from the study.

\section{Group A}

Twenty-one patients (age, 28-71 years; 16 females and 5 males) were treated with ${ }^{131}$ I in the hypothyroid state; $\mathrm{L}-\mathrm{T}_{4}$ was stopped for 37 days; from the 3rd to $22 \mathrm{nd}$ day after $\mathrm{L}_{-} \mathrm{T}_{4}$ withdrawal patients were treated with $\mathrm{T}_{3}$. Patients received ${ }^{131} \mathrm{I}(2.02 \pm 0.22 \mathrm{GBq} ; 54.6 \pm$ $5.9 \mathrm{mCi}$; mean \pm s.D.) $42-180$ days after surgery. On the day of administration of ${ }^{131} \mathrm{I}$, TSH, Tg, and TgAb were measured; $\mathrm{L}_{-} \mathrm{T}_{4}$ was then given again the day after administration of ${ }^{131} \mathrm{I}$.

\section{Group B}

Twenty-one patients (age, 20-67 years; 17 females and 4 males) were treated with ${ }^{131}$ I following the administration of rhTSH (Thyrogen; Genzyme Corp, Cambridge, MA, USA) as described previously (4): the therapeutic activity of ${ }^{131} \mathrm{I}(1.97 \pm 0.18 \mathrm{GBq} ; 53.2 \pm 4.9 \mathrm{mCi}$; mean \pm s.D.) was administered $24 \mathrm{~h}$ after the last injection of rhTSH $(0.9 \mathrm{mg}$ i.m. for two consecutive days); $\mathrm{L}_{-} \mathrm{T}_{4}$ was never stopped during treatment. The time between thyroidectomy and ${ }^{131}{ }^{1}$ treatment was 42-180 days. Serum samples of TSH, $\mathrm{FT}_{4}, \mathrm{FT}_{3}, \mathrm{Tg}$ and anti- $\mathrm{Tg}$ antibodies were taken the day before the first administration of rhTSH. Serum samples for TSH, Tg and $\mathrm{TgAb}$ were also taken 3 days after the last administration of rhTSH. Levels of Tg (functional sensitivity: $0.7 \mathrm{ng} / \mathrm{ml}$ ) were determined with a commercially available IRMA (Thyroglobuline IRMA; CIS-BIO, France). Serum levels of TSH (normal range 0.2-4.0, upper detection limit: $100 \mathrm{mIU} / \mathrm{ml})$, free triiodothyronine $\left(\mathrm{FT}_{3}\right.$, normal range $2.2-5.0 \mathrm{pg}=\mathrm{ml})$, thyroxine $\left(\mathrm{FT}_{4}\right.$, normal range 8.0$18.5 \mathrm{pg}=\mathrm{ml})$ and anti-thyroglobulin antibodies $(\mathrm{TgAb}$, normal range $0.0-70.0 \mathrm{IU}=\mathrm{ml}$ ) were determined with commercially available radioimmunological assay kits (Radim, Pomezia, Italy). Urinary iodine excretion was measured to exclude contamination from stable iodine, using a colorimetric method (CellTech, Torino, Italy). Table 1 summarises pathological (TNM staging, AJCC 2002) (9) stage and histology of cancers in both groups of patients.

\section{Pre-therapy neck scan, post-therapy whole body scan (WBS) and US of the neck}

Twenty-four hours before ablation therapy, a diagnostic activity of ${ }^{131} \mathrm{I}$ ( $\left.18 \mathrm{MBq} ; 0.5 \mathrm{mCi}\right)$ was administered to patients; scintigraphy of the neck and radioiodine uptake was obtained after $24 \mathrm{~h}$, immediately before the therapeutic activity, to verify the extent of the residue and pre-treatment staging. A post-therapy WBS was acquired after 4-6 days. Neck US (7.5-13 MHz; Tecnos, MPX, Esaote, Genoa, Italy) was performed twice by two experienced radiologists to assess the presence and volume of thyroid remnants and to verify the presence of pathological lymph nodes.

\section{Follow-up}

Serum levels of TSH, $\mathrm{FT}_{4}, \mathrm{FT}_{3}, \mathrm{Tg}$ and anti-Tg antibodies were periodically assessed in all patients to verify the degree of TSH suppression and the presence of possible disease relapse. All patients had undetectable levels of $\mathrm{Tg}$ during TSH-suppressive treatment. Six to twelve months after ablation therapy, the outcome of thyroid ablation was assessed in both groups by conventional ${ }^{131}$ I scan and serum Tg measurements. A neck US was also performed. Diagnostic ${ }^{131} \mathrm{I}$ WBS was performed after withdrawal of ${\mathrm{L}-\mathrm{T}_{4}}_{4}$ therapy using the same protocol described for therapy. Images were obtained $48 \mathrm{~h}$ after oral administration of ${ }^{131} \mathrm{I}(185 \mathrm{MBq} ; 5 \mathrm{mCi})$. ${ }^{131}$ I with a double-head gamma camera (Forte; Philips, The Netherlands) using a 3/8 inch thick crystal and a

Table 1 Epidemiological and clinical data of patients from groups $\mathrm{A}$ (hypothyroid) and B (rhTSH).

\begin{tabular}{|c|c|c|c|}
\hline & Hypothyroid & rhTSH & $\boldsymbol{P}$ \\
\hline Patients $(n)$ & 21 & 21 & $\mathrm{~ns}^{\mathrm{a}}$ \\
\hline \multicolumn{4}{|l|}{ Age (years) } \\
\hline $\begin{array}{l}\text { Mean } \pm \text { S.D. } \\
\text { Range }\end{array}$ & $\begin{array}{l}48 \pm 9.9 \\
28-71\end{array}$ & $\begin{array}{l}46.1 \pm 12.3 \\
20-67\end{array}$ & $n s^{a}$ \\
\hline $\operatorname{Sex}(\mathrm{F} / \mathrm{M})$ & $16 / 5$ & $17 / 4$ & $n s^{b}$ \\
\hline \multicolumn{4}{|l|}{ Histology } \\
\hline Papillar & 12 & 11 & \\
\hline $\begin{array}{l}\text { Papillar follicular } \\
\text { variant }\end{array}$ & 6 & 7 & $n s^{c}$ \\
\hline Follicular & 3 & 3 & \\
\hline \multicolumn{4}{|l|}{ TNM staging } \\
\hline $\mathrm{T}_{1}, \mathrm{~N} 0<45$ years & 10 & 11 & $n s^{b}$ \\
\hline $\mathrm{T}_{1}, \mathrm{~N} 0>45$ years & 11 & 10 & \\
\hline
\end{tabular}

Data are expressed as mean \pm S.D. No differences between the two groups are found.

${ }^{\text {a }}$ Student $t$-test.

${ }^{b}$ Fisher's exact test.

${ }^{c} \chi^{2}$ test. 
high-energy, general all-purpose collimator. WBS with anterior and posterior views was acquired after scanning for a minimum of $30 \mathrm{~min}$. Anterior neck/chest spot views were acquired after scanning a minimum of 15 min or after obtaining 150000 counts. Thyroid bed uptake was measured using a thyroid probe (ACN; Scientific Laboratories, Milan, Italy).

\section{Statistical analysis}

Results are expressed as median \pm s.D. for TSH levels and mean \pm s.D. for the remaining laboratory data and as a percentage for the groups of subjects. Student's $t$-test was used to compare laboratory data. Mann-Whitney $U$-test was used for comparing non-parametric data. The $\chi^{2}$ and Fisher's exact tests were used to detect differences in the proportion of cases.

\section{Results}

The administration of ${ }^{131} \mathrm{I}$ was not associated with the development of significant side effects; no neck pain was observed; in few patients there was transient reduction of taste and the most common side effect was nausea.

\section{Ablation therapy}

Serum TSH levels in patients who underwent ${ }^{131} \mathrm{I}$ treatment was $42.5-100 \mathrm{mU} / \mathrm{l}(77.9 \pm 17.1)$ in the hypothyroid patients and 72-100 $\mathrm{mU} / \mathrm{l}(91.0 \pm 9.8)$ in the rhTSH group the day after the second injection of rhTSH. At the time of treatment, the stimulated $\mathrm{Tg}$ values were $3.3 \pm 3.69 \mathrm{ng} / \mathrm{ml}$ in hypothyroid patients (range: $0.2-14.5$ ) and $1.9 \pm 2.15 \mathrm{ng} / \mathrm{ml}$ in patients treated with rhTSH (range: $0.3-7.3$, basal values: $0.2-$ 1.3). Values of TSH, FTH, before and after treatment are reported in Table 2. After surgery, all patients of the hypothyroid group showed residual thyroid tissue in the thyroid bed at the pre-treatment neck scan (neck iodine uptake: $4.7 \pm 4.55 \%$, range: $0.8-16.6 \%$ ) and at posttreatment scan. Patients treated with rhTSH all showed ${ }^{131}$ I uptake of thyroid remnants at the post-treatment scan, but 6 out of 21 patients did not show any uptake at the pre-treatment scan and the average uptake in the neck $(1.38 \pm 1.41 \%$, range: $0-5.4 \%)$ was lower when compared with the hypothyroid patients (Table 2). The injection of rhTSH was well tolerated.

Thyroid remnants were detected by US in 5 out of 21 patients of group A and in 4 out of 21 of group B (vol: $0.34 \pm 0.26 \mathrm{ml}$ and $0.53 \pm 0.40 \mathrm{ml}$, groups A and B respectively). Thyroid remnant volume was never greater than $1 \mathrm{ml}$. No correlation between the presence and size of remnants detected by US, ${ }^{131}$ I uptake, stimulated Tg levels and the efficacy of ablation was observed. Results of urinary iodine were within normal limits in all patients.

\section{Follow-up}

At the follow-up, in the hypothyroid group WBS was negative (no visible uptake in the thyroid bed) in 20 out of 21 patients $(95.2 \%)$. One patient showed clear visible uptake in the thyroid bed $(0.9 \%)$ with $\mathrm{Tg}$ of $2.4 \mathrm{ng} / \mathrm{ml}$; in this patient, the pre-treatment uptake was $1.0 \%$. No patient with high pre-treatment uptake showed any residual uptake at follow-up, even patients with uptake as high as $16.6 \%$. Another patient had Tg levels above $1 \mathrm{ng} / \mathrm{ml}(1.6 \mathrm{ng} / \mathrm{ml})$ without any visible uptake in the thyroid bed; in this patient, the pre-treatment Tg was 6.5. One patient had undetectable Tg values at the time of treatment (less than $0.2 \mathrm{ng} / \mathrm{ml}$ ) and $\mathrm{Tg}$ could not be used as a marker of successful ablation. In total, 18 out of 20 patients $(90.0 \%)$ had $\mathrm{Tg}$ levels below $1 \mathrm{ng} / \mathrm{ml}$.

In the group of patients treated with rhTSH, WBS was negative in 19 out of 21 patients $(90.5 \%)$. Patients with visible uptake in the thyroid bed had uptake values of 0.53 and $0.9 \%$ and $\mathrm{Tg}$ levels of 0.2 and $0.6 \mathrm{ng} / \mathrm{ml}$ respectively; their pre-treatment uptake values were 1.6 and $1.8 \%$. Three patients had Tg levels higher than

Table 2 Summary of results of patients from groups A (hypothyroid) and B (rhTSH): no differences were noted between the two groups with respect to $\mathrm{Tg}$ levels at the time of treatment; as expected, patients from group $B$ were not hypothyroid; the pre-treatment uptake in patients from group B was significantly lower as a result of incomplete rhTSH stimulation (only one dose of rhTSH before the diagnostic dose of ${ }^{131} \mathrm{I}$ ); high rates of ablation were noted in patients from both groups considering both ablation criteria ( $\mathrm{Tg}$ levels or ${ }^{131} \mathrm{I}$ uptake) with no statistical differences.

\begin{tabular}{llll}
\hline & Hypothyroid & rhTSH & $\boldsymbol{P}$ \\
\hline TSH (the day of treatment) & $77.9 \pm 17.1^{\mathrm{a}}$ & $91.00 \pm 9.8^{\mathrm{a}}$ & $\mathrm{ns}^{\mathrm{b}}$ \\
Tg after stimulus (at treatment) & $3.3 \pm 3.7$ & $1.9 \pm 2.15$ & $\mathrm{~ns}^{\mathrm{b}}$ \\
$\mathrm{Tg}$ 6-12 months after treatment (after withdrawal) & $0.38 \pm 0.55$ & $0.42 \pm 0.38$ & $\mathrm{~ns}^{\mathrm{b}}$ \\
$\mathrm{FT}_{3}$ the day of treatment & $1.27 \pm 0.2$ & $2.77 \pm 0.43$ & $<0.001^{\mathrm{b}}$ \\
$\mathrm{FT}_{4}$ the day of treatment & $4.7 \pm 3.1$ & $13.12 \pm 2.2$ & $<0.001^{\mathrm{b}}$ \\
Pre-treatment uptake & $4.7 \pm 4.55$ & $1.38 \pm 1.41$ & $0.004^{\mathrm{b}}$ \\
Uptake 6 months after treatment & $0.38 \pm 0.55$ & $0.22 \pm 0.24$ & $\mathrm{~ns}^{\mathrm{b}}$ \\
Ablation (Tg<1 ng/ml) & $90.0 \%(18 / 20)$ & $85.0(17 / 20)$ & $\mathrm{ns}^{\mathrm{c}}$ \\
Ablation (no visible uptake) & $95.2 \%(20 / 21)$ & $90.5(19 / 21)$ & $\mathrm{ns}^{\mathrm{c}}$ \\
\hline
\end{tabular}

${ }^{\mathrm{a}}$ Median.

'Mann-Whitney U-test.

'Fisher's exact test. 
$1 \mathrm{ng} / \mathrm{ml}$ at follow-up $(1.37,1.08$ and $1.12 \mathrm{ng} / \mathrm{ml})$ with no visible uptake in the thyroid bed. One patient had undetectable $\mathrm{Tg}$ values at the time of treatment (less than $0.2 \mathrm{ng} / \mathrm{ml}$ ); and $\mathrm{Tg}$ could not be used as a marker for successful ablation. The total number of patients who could be analysed for Tg values, therefore, was 20 . In total, 17 out of 20 patients $(85.0 \%)$ had Tg levels below $1 \mathrm{ng} / \mathrm{ml}$. Data of both groups are summarised in Table 2. Data about TSH and FTH, at follow-up, were similar to those before treatment with ${ }^{131} \mathrm{I}$ and are not reported.

\section{Discussion}

Ablation therapy by ${ }^{131} \mathrm{I}$ in patients affected by differentiated thyroid carcinoma, who underwent thyroidectomy is used to reduce tumour recurrence and mortality. In low-risk patients, however, its role is still being discussed (10).

Administration of ${ }^{131} \mathrm{I}$, although well tolerated in the vast majority of patients, may have side effects (11). It is, therefore, necessary to select patients who will benefit from treatment and to identify the most effective protocol that delivers the lowest radiation dose still compatible with effective treatment and that provides the best quality of life.

Indication to treatment has recently been developed on the basis of risk stratification calculated according to the TNM staging system and the results of imaging studies $(10,12,13)$. It is now accepted that patients with very low risk do not need ablation therapy, whereas in high-risk patients it is always indicated and must be performed under hypothyroidism. The indication to treatment in patients at low risk has not yet been completely elucidated: is ablation therapy really necessary? Which is the activity of ${ }^{131}$ I to be used, and which is the best protocol for preparation to treatment: rhTSH administration or hypothyroidism?

The use of rhTSH for the preparation of patients who must undergo ablation therapy has recently been authorised for patients at low risk using $3.7 \mathrm{GBq}$ $(100 \mathrm{mCi})$. Using this procedure, it is not necessary to induce hypothyroidism and, although it delivers the same radiation dose to the thyroid remnants, the total body dose is reduced by about $35 \%$ as a consequence of faster renal clearance of iodine compared with patients treated in hypothyroidism (14). The use of rhTSH for ablation therapy with low activities of ${ }^{131} \mathrm{I}$ is still a matter of debate. Low-activity $(1.11 \mathrm{GBq} ; 30 \mathrm{mCi})$ ablation therapy using rhTSH for the preparation of patients has given conflicting results $(6,7)$. In one study, the use of rhTSH for the preparation of patients proved less effective compared with the preparation by hypothyroidism (7). In a different study, low-activity ablation therapy using rhTSH was equally effective compared with the preparation by hypothyroidism (6). A possible explanation for the lower efficacy described in certain studies could be ascribed to the low activity of
${ }^{131} \mathrm{I}(1.11 \mathrm{GBq} ; 30 \mathrm{mCi})$ that, when using rhTSH as a preparation, could be insufficient. It is known that acute stimulation by rhTSH is associated with less efficient activation of NIS, compared with chronic stimulation induced by hypothyroidism (6). Also, a recent study on the use of rhTSH for the preparation of patients for ablation therapy showed that the efficacy of $1.85 \mathrm{GBq}$ $(50 \mathrm{mCi})$ of ${ }^{131} \mathrm{I}$ was comparable with that of $3.7 \mathrm{GBq}$ $(100 \mathrm{mCi})(8)$. The patient population of this study, however, was rather inhomogeneous with respect to TNM staging, persistence of the disease and extent of residual thyroid tissue.

In the present study, we compared the efficacy of lowactivity $(2.0 \mathrm{GBq} ; 54 \mathrm{mCi})$ ablation therapy, in a homogeneous group of patients at low risk prepared by hypothyroidism (group A) or rhTSH (group B). Efficacy was determined by follow-up WBS and Tg measurement in hypothyroidism. The role of thyroid remnants volume and of ${ }^{131} \mathrm{I}$ uptake was also assessed.

High rates of ablation were observed in both groups. If $\mathrm{Tg}(<1 \mathrm{ng} / \mathrm{ml})$ levels were used to assess efficacy of treatment, in group A the rate of efficacy was $90.0 \%$ and in group B $85.0 \%(P=n s ;$ group A versus group B, Fisher's exact test). Out of 20 patients in group A, 2 had values of stimulated $\mathrm{Tg}$ greater than $1 \mathrm{ng} / \mathrm{ml}$ and 3 in group B. In these patients from both groups, stimulated $\mathrm{Tg}$ levels were only slightly $>1 \mathrm{ng} / \mathrm{ml}(1.08-2.4 \mathrm{ng} / \mathrm{ml})$ and neck US was negative for the detection of persistent/recurrent disease. Although long-term follow-up data are not available, it is unlikely that low levels of $\mathrm{Tg}$, although $>1 \mathrm{ng} / \mathrm{ml}$, represent a significant risk for recurrence in low-risk patients (15). All patients with $\mathrm{Tg}$ levels $>1 \mathrm{ng} / \mathrm{ml}$ after ablation therapy had a low pre-therapy uptake value $(<2 \%)$, whereas all patients with higher uptake $(>10 \%)$ showed effective treatment. These data suggest that low pre-therapy uptake values, when using low activities of ${ }^{131} \mathrm{I}$, might be associated with lower efficacy.

If no visible neck uptake of ${ }^{131}$ I was considered as successful ablation, the rate of ablation in both groups was even higher: $95.2 \%$ in group A and 90.5\% in group $B$, with no differences between the two groups $(P=n s$; group A versus group B, Fisher's exact test). Visible uptake was associated with very low neck uptake values $(0.3 \%$ and $0.9 \%)$ and $\mathrm{Tg}$ levels $<1 \mathrm{ng} / \mathrm{ml}$ with the exception of one patient with $\mathrm{Tg}$ levels of $2.4 \mathrm{ng} / \mathrm{ml}$. Also, in this case, it is possible to speculate that the presence of visible (low) uptake in association with undetectable or low values of $\mathrm{Tg}$ is not associated with significant risk of recurrence (15). Nevertheless, patients with no complete ablation, particularly those with Tg levels $>1 \mathrm{ng} / \mathrm{ml}$, should be followed up in time.

In this study, neck uptake and scintigraphy was evaluated by $18 \mathrm{MBq}(0.5 \mathrm{mCi})$ of ${ }^{131} \mathrm{I}$ administered $24 \mathrm{~h}$ before the therapeutic activity. It is generally accepted that a low activity of ${ }^{131} \mathrm{I}$ administered $24 \mathrm{~h}$ before the therapy activity does not cause thyroid stunning (16). As expected on the basis of the 
incomplete (a single dose) rhTSH stimulation, in patients of group B, the pre-therapy neck uptake was on average lower compared with that of group $A$ : $1.38 \pm 1.41$ vs $4.7 \pm 4.55(P=0.004$; group $\mathrm{B}$ versus group A; Mann-Whitney $U$ test); in six patients, there was no visible uptake before therapy that became visible at the post-therapy WBS. By contrast, all patients of group A showed visible uptake at the pre-therapy neck scintigraphy. In patients of group B, the pre-therapy neck scintigraphy was performed with a low activity of ${ }^{131} \mathrm{I}$ (18 MBq; $\left.0.5 \mathrm{mCi}\right) 24 \mathrm{~h}$ after a single injection of rhTSH, whereas the post-therapy WBS was obtained with the therapy activity, administered $24 \mathrm{~h}$ after the second injection of rhTSH. The low visualisation of thyroid remnants does not seem to affect the therapeutic efficacy; it could, however, hamper the assessment of the extent of thyroid remnants and the presence of areas of uptake external to the thyroid bed in patients who are prepared for ablation with rhTSH. The measurement of pre-therapy ${ }^{131}$ I uptake and neck scintigraphy, therefore, is relevant, although it does not correlate with the rate of successful ablation.

All patients underwent neck US at the time of treatment. Although visible neck uptake of ${ }^{131}$ I was detectable in the thyroid bed of all patients of both groups at the post-therapy WBS, the presence of thyroid remnants as assessed by neck US was detected in less than half of patients in both groups with a maximum volume of $<1 \mathrm{ml}$. No correlation between remnant size measured at US, ${ }^{131}$ I uptake and ablation efficacy was observed. This suggests that in the cases of small thyroid remnants, it is not possible to calculate the dose delivered. Dosimetry-based ablation therapy is, therefore, not always feasible on the basis of US results and, in this group of patients at low risk, seems not necessary.

\section{Conclusions}

Our randomised prospective clinical trial showed that low-activity ablation therapy with $2 \mathrm{GBq}(54 \mathrm{mCi})$ induced high rates of effective ablation in low-risk patients prepared by hypothyroidism and that the same activity of ${ }^{131}$ I after rhTSH stimulation has a similar efficacy. The results obtained in a homogeneous patient population confirm those obtained in a recent paper on the use of $1.85 \mathrm{GBq}(50 \mathrm{mCi})$ after rhTSH stimulation but in patients with a more heterogeneous staging (8). The measurement of pre-therapy ${ }^{131}$ I uptake and the presence of thyroid remnants with volume smaller than $1 \mathrm{ml}$ at US examination did not affect the rate of ablation efficacy. The major role of neck US is for detecting pathological lymph nodes. The use of rhTSH with low activities of ${ }^{131} \mathrm{I}(1.85 \mathrm{GBq} ; 50 \mathrm{mCi})$, compared with the procedure authorised in Europe for ablation therapy (rhTSH $+3.7 \mathrm{GBq} ; 100 \mathrm{mCi}$ ), has the advantages of reducing patient radiation exposure and needing a shorter hospitalisation.
Therefore, in low-risk patients, this protocol might combine optimal efficacy and minimal discomfort for the patient. A limitation of this study, however, is the rather small number of patients studied; these results, therefore, need to be confirmed in a larger series of patients. Further studies are also necessary to improve the protocol to give complete assessment of thyroid remnants also after rhTSH stimulation and to find out what is the minimum effective activity that can be used with rhTSH for ablation therapy in low-risk patients.

\section{Declaration of interest}

There is no conflict of interest that could be perceived as prejudicing the impartiality of the research reported.

\section{Funding}

This research did not receive any specific grant from any funding agency in the public, commercial or not-for-profit sector.

\section{Acknowledgements}

The technical assistance of Paolo Dello Russo and Cynthia Trojani is greatly acknowledged. The experiments comply with the current Italian laws.

\section{References}

1 Mazzaferri EL \& Jhiang SM. Long-term impact of initial surgical and medical therapy on papillary and follicular thyroid cancer. American Journal of Medicine 199497 418-428.

2 De Groot LJ, Kaplan EL, McMormick M \& Strauss F. Natural history, treatment and course of papillary thyroid carcinoma. Journal of Clinical Endocrinology and Metabolism 199071 414-424.

3 Pacini F, Schlumberger M, Harmer C, Berg GG, Cohen O, Duntas L, Jamar F, Jarzab B, Limbert E, Lind P, Reiners C, Sanche Franco F, Smit J \& Wiersinga W. Post-surgical use of radioiodine $\left({ }^{131} \mathrm{I}\right)$ in patients with papillary and follicular thyroid cancer and the issue of remnant ablation: a consensus report. European Journal of Endocrinology 2005153 651-659.

4 Pacini F, Ladenson PW, Schlumberger M, Driedger A, Luster M, Kloos T, Sherman S, Haugen B, Corone C, Molinaro E, Elisei R, Ceccarelli C, Pinchera A, Wahl RL, Leboulleux S, Ricard M, Yoo J, Busaidy NL, Delpassand E, Hanscheid H, Felbinger R, Lassmann M \& Reiners C. Radioiodine ablation of thyroid remnants after preparation with recombinant human thyrotropin in differentiated thyroid carcinoma: results of an international, randomized, controlled study. Journal of Clinical Endocrinology and Metabolism $200691926-932$.

5 European Medicines Agency. EMEA/H/C/220/II/18, Decision C(2005) 478 of 23/02/2005 London: European Medicines Agency, 2005.

6 Barbaro D, Boni G, Meucci G, Simi U, Lapi P, Orsini P, Pasquini C, Piazza F, Caciagli M \& Mariani G. Radioiodine treatment with $30 \mathrm{mCi}$ after recombinant human TSH stimulation in thyroid cancer: effectiveness for postsurgical remnants ablation and possible role of iodine content in L-thyroxine in the outcome of ablation. Journal of Clinical Endocrinology and Metabolism $2003 \mathbf{8 8}$ 4110-4115.

7 Pacini F, Molinaro E, Castagna MG, Lippi F, Ceccarelli C, Agate L, Elisei R \& Pinchera A. Ablation of thyroid residues with $30 \mathrm{mCi}^{131} \mathrm{I}$ : a comparison in thyroid cancer patients prepared with recombinant human TSH or thyroid hormone withdrawal. Journal of Clinical Endocrinology and Metabolism 200287 4063-4068. 
8 Pilli T, Brianzoni E, Capoccetti F, Castagna MG, Fattori S, Poggiu A, Rossi G, Ferretti F, Guarino E, Burroni L, Vattimo A, Cipri C \& Pacini F. A comparison of $1850(50 \mathrm{mCi})$ and $3700 \mathrm{MBq}$ (100 mCi) 131-iodine administered doses for recombinant thyrotropin-stimulated postoperative thyroid remnant ablation in differentiated thyroid cancer. Journal of Clinical Endocrinology and Metabolism 200792 3542-3546.

9 American Joint Committee on Cancer. Thyroid. In AJCC Cancer Staging Handbook, edn 6, pp 89-98. Eds FL Greene, DL Page, ID Fleming, AG Fritz, CM Balch, DG Haller \& M Morrow, New York: Springer, 2002 (ch 8).

10 Pacini F, Schlumberger M, Dralle H, Elisei R, Smit JWA, Wiersinga W \& European Thyroid Cancer Taskforce. European consensus for the management of patients with differentiated thyroid carcinoma of the follicular epithelium. European Journal of Endocrinology 2006154 787-803.

11 Rubino C, de Vathaire F, Dottorini ME, Hall P, Schvartz C, Couette JE, Dondon MG, Abbas MT, Langlois C \& Schlumberger M. Second primary malignancies in thyroid cancer patients. British Journal of Cancer $2003 \mathbf{8 9} 1638-1644$.

12 Cooper DS, Doherty GM, Haugen BR, Kloos RT, Lee SL, Mandel SJ, Mazzaferri EL, McIver B, Sherman SI \& Tuttle RM. Management guidelines for patients with thyroid nodules and differentiated thyroid cancer: the American Thyroid Association Guidelines Taskforce. Thyroid 200616 109-142.
13 British Thyroid Association, Royal College of Physicians. In Report of the Thyroid Cancer Guidelines Update Group, Guidelines for the Management of Thyroid Cancer, edn 2, Ed. P Perros, London: Royal College of Physicians, 2007.

14 Hänscheid H, Lassmann M, Luster M, Thomas S, Pacini F, Ceccarelli C, Ladenson PW, Wahl RL, Schlumberger M, Ricard M, Driedger A, Kloos RT, Sherman SI, Haugen BR, Carriere V, Corone C \& Reiners C. Iodine biokinetics and dosimetry in radioiodine therapy of thyroid cancer: procedures and results of a prospective international controlled study of ablation after rhTSH or hormone withdrawal. Journal of Nuclear Medicine 2006 $47648-654$.

15 Torlontano M, Attard M, Crocetti U, Tumino S, Bruno R, Costante G, D'Azzò G, Meringolo D, Ferretti E, Sacco R, Arturi F \& Filetti S. Follow-up of low risk patients with papillary thyroid cancer: role of neck ultrasonography in detecting lymph node metastases. Journal of Clinical Endocrinology and Metabolism 2004 89 3402-3407.

16 Morris LF, Waxman AD \& Braunstein GD. Thyroid stunning. Thyroid 200313 333-340.

Received 3 December 2008

Accepted 11 December 2008 